\title{
Estimating suspended sediment concentrations from turbidity measurements and the calibration problem
}

\author{
Jean P. G. Minella, ${ }^{1 *}$ Gustavo H. Merten, ${ }^{1}$ José M. Reichert ${ }^{2}$ and Robin T. Clarke ${ }^{1}$ \\ ${ }^{1}$ Hydraulic Research Institute, Federal University of Rio Grande do Sul, Box 15029, CEP 91501-970, Porto Alegre, RS, Brazil \\ ${ }^{2}$ Soils Department, Federal University of Santa Maria, CCR, CEP 97105-900, Santa Maria, RS, Brazil
}

\begin{abstract}
:
In situ turbidity meters are being increasingly used to generate continuous records of suspended sediment concentration in rivers. However, the usefulness of the information obtained depends heavily on the existence of a close relationship between fluctuations in suspended sediment concentration and turbidity and the calibration procedure that relates suspended sediment concentration to the turbidity meter's signal. This study assesses the relationship between suspended sediment concentration and turbidity for a small $\left(1.19 \mathrm{~km}^{2}\right)$ rural catchment in southern Brazil and evaluates two calibration methods by comparing the estimates of suspended sediment concentration obtained from the calibrated turbidity readings with direct measurements obtained using a USDH 48 suspended sediment sampler. With the first calibration method, the calibration relationship is derived by relating the turbidity readings to simultaneous measurements of concentration obtained from suspended sediment samples collected from the vicinity of the turbidity probe during flood events. With the second method, the calibration is based on the readings obtained from the turbidity meter when the probe immersed in samples of known concentration prepared using soils collected from the catchment. Overall, there was a close link between fluctuations in suspended sediment concentration and turbidity in the stream at the outlet of the catchment, and the estimates of sediment concentration obtained using the first calibration method corresponded closely with the conventionally measured sediment concentrations. However, use of the second calibration method introduced appreciable errors. When the estimated sediment concentrations were compared with the measured values, the mean errors were $\pm 122 \mathrm{mg} \mathrm{l}^{-1}$ and $+601 \mathrm{mg}^{-1}$ for the first and second calibration procedures respectively. Copyright (c) 2007 John Wiley \& Sons, Ltd.
\end{abstract}

KEY WORDS turbidity; suspended sediment concentration; sediment transport; particle size; calibration

Received 11 June 2006; Accepted 13 March 2007

\section{INTRODUCTION}

\section{The context}

Accurate determination of suspended sediment concentrations (SSCs) and associated suspended sediment fluxes in rivers is of great importance for many aspects of water resource development and river basin management, including estimation of the useful life of reservoirs (Carvalho, 1994; Bordas and Semmelmann, 1997), evaluation of land use and management impacts (Dunne, 1979; Morgan, 1995; Kasai et al. 2005; Kimoto et al., 2002; Walling, 2006), and quantifying sedimentassociated nutrient and contaminant fluxes (Horowitz and Elrick, 1987; Martin and McCulloch, 1999; Owens and Walling, 2002; Walling et al., 2003). The traditional approach to establishing the suspended load of a river involves measuring the flow rate and the manual collection of water samples, using an appropriate sampling device, to determine the SSC (e.g. WMO, 2003). Ideally, the sampling frequency should permit reliable interpolation of the concentration record and should be linked to the rate of water-level change, since sediment flux is greatest during flood events (Walling and Webb, 1988;

\footnotetext{
* Correspondence to: Jean P. G. Minella, Hydraulic Research Institute, Federal University of Rio Grande do Sul, Box 15029, CEP 91501-970, Porto Alegre, RS, Brazil. E-mail: jminella@ppgiph.ufrgs.br
}

WMO, 2003). However, operational and economic constraints frequently limit sampling frequency and the collection of samples during times of flood. In view of the many problems associated with the use of sediment rating curves to extrapolate the data provided by a small number of samples, by establishing a relationship between sediment concentration and water discharge (e.g. Walling and Webb, 1981, 1988), there is considerable interest in the use of surrogate measurements to provide information on the variation of sediment concentrations through time and, thus, to generate a continuous record of sediment concentration (e.g. Walling and Collins, 2000). Turbidity has been widely used as a surrogate for SSC, since it is easily monitored and recorded and turbidity probes can be readily deployed in situ in the river channel (Glysson and Gray, 2002; Lewis, 2002; Schoellhamer, 2002; Old et al., 2003). In this case, turbidity is continuously recorded and converted to a record of SSC using an empirically derived calibration relationship relating SSC to turbidity.

Since SSCs will frequently fluctuate rapidly during storm events in small- and medium-sized catchments, sampling frequency during flood events is commonly a decisive factor in obtaining reliable estimates of sediment flux (Williams, 1989; Lane et al., 1997). Continuous turbidity monitoring can therefore offer important benefits 
in such catchments in terms of generating accurate sediment flux estimates, as well as providing detailed records of storm-period fluctuations in sediment concentration, which can in turn be used to develop an improved understanding of their suspended sediment dynamics.

\section{The physical background}

Continuous records of SSC can be obtained simply and conveniently by monitoring the turbidity of the river water, provided there is a close relationship between fluctuations in sediment concentration and turbidity, and the physical principles of turbidimetry or nephelometry are respected when calibrating the equipment's sensor or probe (Lawler, 2005; Lawler et al., 2006; DaviesColley and Smith, 2005). Turbidity can be defined as an optical property of a water sample, which measures the degree to which a beam of light passing through the water is absorbed or scattered. The International Standards Organization (ISO) further defines turbidity as the 'reduction of transparency of a liquid caused by the presence of undissolved matter' (Lawler, 2005). Turbidity can be measured by turbidimetry or nephelometry. The former measures the attenuation or absorption of a ray of light as it passes through a liquid medium and the latter measures the degree of scattering that the light undergoes. Scattering refers to the light that is reflected or refracted by the surface of a particle, and absorption refers to light that is transformed into other forms of energy (such as heat) upon collision with a particle.

The complex interaction between the energy of the incident beam of light and the wide range of potential suspended particles of varying origin and composition (e.g. silt, clay, algae, plankton, micro-organisms and organic matter), as well as possible problems of probe fouling, frequently result in a weak association between SSC and turbidity. Furthermore, many factors, including the mineralogy and organic composition of the particles, their size and shape, the refraction index of both the particles and the medium, and the wavelength of the incident light will influence the precise form of this relationship (Lawler, 2005). As a result, it is important to derive a site-specific calibration relating SSC to turbidity when using turbidity as a surrogate for measurements of SSC.

\section{Calibration}

There is no standard convention for calibrating a turbidity meter to provide measurements of SSC. However, two basic steps are commonly involved. The first involves using a standardized suspension to test equipment function and to confirm sensor efficiency and stability. This step is important for documenting instrument drift and other evidence of temporal variability in the probe's response to changes in concentration and, thus, the concentration-turbidity relationship, as well as for comparing the response of different sensors or instruments and evaluating their sensitivity, linearity and reproducibility (Vanous et al., 1982). According to Vanous et al. (1982), the standardized suspension must be accurate, stable and easy to use. Formazin has been widely adopted as the primary standard for nephelometers, but health and safety concerns (formazin is a known carcinogen) have prompted the use of other standards, including, for example, powdered carbon, polymers and latex and glass beads. The second step focuses on establishing the precise relationship between SSC and the turbidity signal. Since this calibration relationship will depend on the properties of both the sediment particles and the water, it will be site-specific and should, therefore, be established for every measuring site or catchment. This relationship can be derived either in situ, by relating the turbidity signal to values of SSC obtained for samples collected from the river in the vicinity of the probe over a range of flow conditions and ambient concentrations, or in the laboratory, by placing the probe in suspensions of known concentration, representative of the suspended sediment transported by the river, and covering a range of different sediment concentrations (e.g. Lawler and Brown 1992; Lewis, 2002; Old et al., 2003).

\section{Data reliability and errors}

Although turbidity meters are widely accepted as providing a viable means of obtaining continuous SSC data, it is important to consider the possible errors arising from their use (e.g. Landers, 2002). Assuming that there is a close relationship between fluctuations in sediment concentration and turbidity in a stream and considering, first, the reliability of the point measurements of SSC provided by a turbidity probe installed at a particular point in the river cross-section, errors may stem from several sources, including (i) instrument errors associated with the equipment used, (ii) systematic errors introduced by the calibration procedure employed, and (iii) methodological errors caused by indirect measurement of the variable under study. Instrument errors can be both systematic and random, reflecting, for example, instrument drift and instability in the signal caused by variations in the voltage of the electrical supply and changes in ambient temperature (e.g. Souza, 2005). Systematic errors can result from the use of different calibration procedures, causing significant differences in sediment concentration estimates for a given turbidity value. For example, Teixeira and Caliari (2005) analysed errors associated with the use of regression models incorporating independent variables other than turbidity TUR to estimate SSC. For the simple regression model, $\mathrm{SSC}=f(\mathrm{TUR})$, the maximum error was $28 \%$, but when the model used colour and the median grain size of the sediment $D_{50}$ as additional variables, SSC $=f\left(\right.$ TUR, Colour, $D_{50}$ ), the maximum error was reduced to $23.3 \%$. However, when the data were separated in to the two concentration classes $20-320 \mathrm{mg}$ $1^{-1}$ and 320-640 $\mathrm{mg}^{-1}$, the errors associated with the regression model were $11 \%$ and $9 \%$ respectively. Similarly, methodological errors can, for example, result from scatter in the data used to derive the calibration relationship due to temporal variation in the properties of 
the suspended particles (e.g. size, shape and mineralogy) and in water colour, which will affect the relationship between the two variables (Vanous et al., 1982; Gippel, 1995).

Further uncertainties are introduced if the point measurement of sediment concentration is assumed to be representative of the cross-section, since it is well known that SSCs will vary through the cross-section. A location towards the edge of the channel may not be representative of the cross-section and, if the position of the probe is fixed, the precise relationship between the concentration at the measuring point and the mean concentration in the cross-section may vary with changing stage and discharge. Based on the above and other considerations, Schoellhamer (2002) identifies three key considerations for minimizing errors when operating sediment-turbidity monitoring stations: (i) the sensor installation, and including location in the cross-section, maintenance and cleaning; (ii) optimal sensor calibration; (iii) effective and accurate data processing.

\section{Problem definition and objectives}

This paper focuses on the problems and uncertainties associated with the use of turbidity as a surrogate measure for SSC and the calibration of turbidity monitoring equipment and, more particularly, the derivation of the calibration relationship required to derive a continuous time-series of sediment concentration from the turbidity record. As noted above, these calibration problems involve both systematic errors associated with the calibration procedure employed and methodological errors linked to the lack of a unique relationship between sediment concentration and turbidity. It directs particular attention to the practice of using the finer fraction of soil samples collected from a catchment to prepare suspensions of known concentration, which are then used to calibrate the turbidity probe either in the laboratory or at the monitoring location (with the probe removed from the river). This practice is being increasingly employed in Brazil, where it is recommended by the manufacturer of the turbidity monitoring equipment and where it is seen to offer both a viable alternative to in situ calibration and several operational and cost advantages. It avoids the requirement to collect suspended sediment samples from the river and the need to visit the river during a range of flow conditions to collect these samples. Furthermore, it permits the calibration relationship to be established rapidly in a single exercise, thereby avoiding the need to wait until the full range of ambient concentrations has been sampled, and it provides sediment concentration data immediately the turbidity recording equipment is installed. Although it may seem reasonable to assume that the fine (e.g. $<63 \mu \mathrm{m})$ fraction of soil samples collected from a catchment can be used to produce suspensions that will be reasonably representative of the sediment transported by the river or stream draining that catchment, since they will have a similar mineralogical composition, there is a need to recognize that the transported sediment will generally be characterized by a different (i.e. finer) grain size distribution to the parent soil (e.g. Peart and Walling, 1982). Since grain size exerts a key control over mineralogy and organic matter content, contrasts in grain size composition between the soil and sediment may result in contrasts in mineralogy and organic matter content. Furthermore, the transported sediment may include autochthonous organic material, which will introduce further contrasts between the soil and the sediment. Since grain size, mineralogy and organic content are known to exert an important influence on the precise form of the sediment concentration-turbidity relationship (e.g. Foster et al., 1992), it is clear that use of sediment samples synthesized from catchment soils to calibrate a turbidity probe could introduce significant errors in the resulting sediment concentration data. In addition, further uncertainty in the calibration relationship could be introduced by the effects of in-stream flocculation and aggregation processes (see Droppo et al. (2005)) in influencing the in situ or effective grain size distribution of the natural suspended sediment relative to that of the soil comprising the synthesized samples and by the use of water that is unrepresentative of the natural river in terms of dissolved organic matter and colour. Even if the soil used to produce the synthetic suspended sediment had essentially identical properties to the suspended sediment, one should not expect an identical concentration-turbidity relationship for both, since in-stream aggregation and flocculation processes could increase the effective grain size of the suspended sediment in the river and reduce the turbidity associated with a particular sediment concentration.

Although the above discussion has emphasized the various problems and uncertainties associated with the use of synthetic suspended sediment samples produced using soil samples collected from the catchment to calibrate a turbidity probe, there is little information on the potential magnitude of the errors that could be introduced into the resulting record of SSC by the calibration procedure. This paper reports the results of an investigation undertaken in a small catchment in southern Brazil aimed at establishing the magnitude of these errors, by comparing the SSC estimates obtained when calibration was performed both in the laboratory, using soils collected from the study catchment, and in situ, using suspended sediment samples collected from the river during flood events of different magnitude.

\section{METHODS}

\section{The study catchment and the monitoring site}

The study was undertaken in a small experimental catchment located on the upper northeast slope of the Rio Grandense plateau, in the municipality of Arvorezinha, Rio Grande do Sul, Brazil. The catchment has an area of $1.19 \mathrm{~km}^{2}$ and is a headwater of the Guaporé River in southern Brazil (Figure 1). The underlying geology of the catchment is predominantly basalt, and the topography is characterized by rolling terrain in the upper part of 

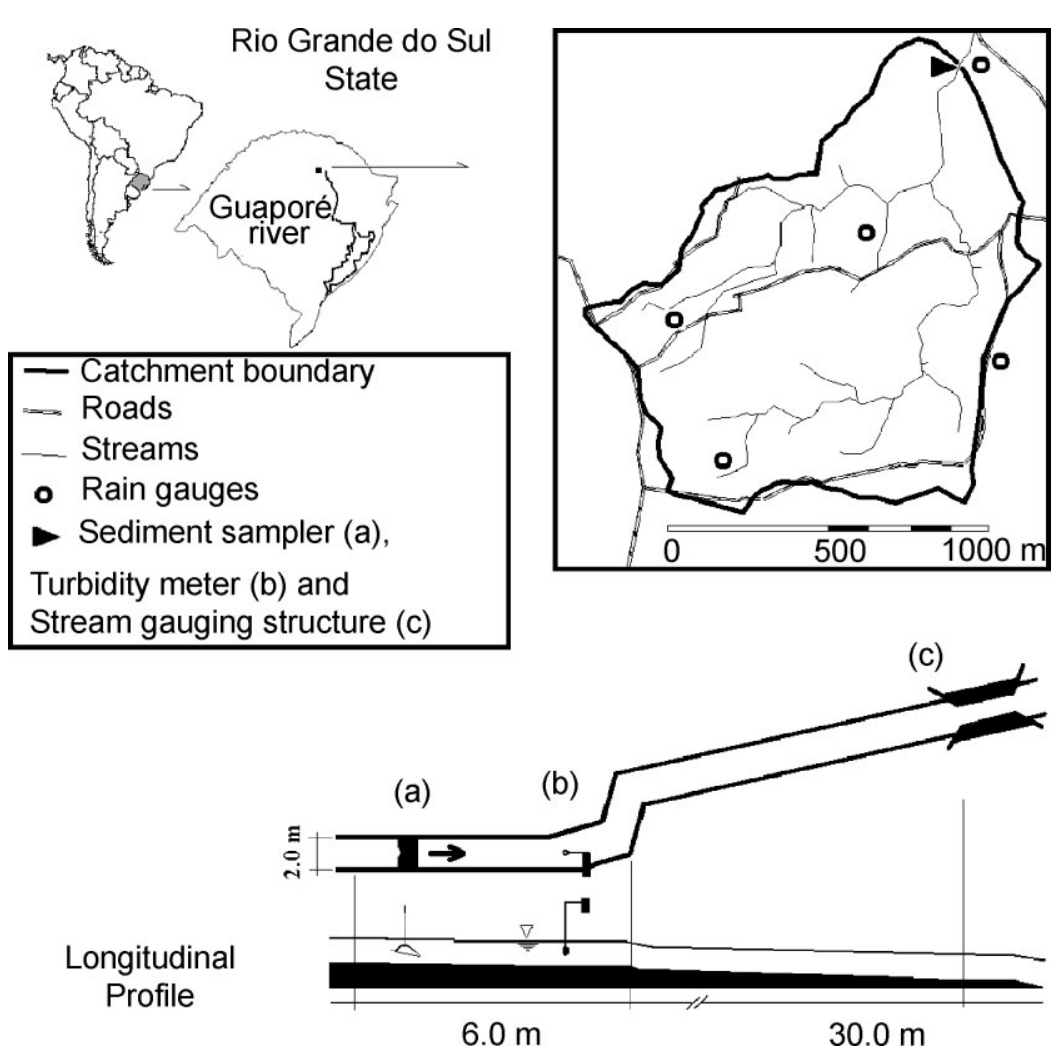

Figure 1. The Arvorezinha experimental catchment, its location and the flow and sediment monitoring installations

the catchment (7\% average slope) and by steeply rolling terrain (17\% average slope) with short slopes and box canyons in the lower two-thirds of the catchment. The altitude varies between 560 and $740 \mathrm{~m}$. The predominant soils are Hapludults and Dystrudepts, based on the USDA soil taxonomy system (USDA, 1975), with an average depth of $0.5 \mathrm{~m}$. According to the Köppen classification, the region's climate is Cfb subtropical super-humid mesothermic, with cool temperatures in the summer and severe frosts in the winter. The mean annual precipitation of $1605 \mathrm{~mm}$ is evenly distributed throughout the year (Minella, 2003).

The catchment's physiographic characteristics are responsible for its ecological fragility. The cropping system is very intense and generates problems for sustainable use of the soil resource. Tobacco is the predominant crop in this catchment, occupying $55 \%$ of the land area, and surface runoff and soil erosion occur frequently. The mean annual sediment yield is estimated to be $\sim 145 \mathrm{t} \mathrm{km}^{-2}$, with transport varying through the year in response to seasonal changes in plant cover and rainfall erosivity (Merten and Minella, 2005).

The monitoring section at the catchment outlet was selected because it is characterized by flow parallel to the straight channel margin, has good bank stability, and is easily accessible. The channel section has a rectangular cross-section $2.0 \mathrm{~m}$ wide and $0.6 \mathrm{~m}$ high. Flow in the channel is turbulent, producing a relatively uniform distribution of SSC within the cross-section. A Parshall flume equipped with a pressure-sensing limnograph was used to measure the flow. The distance between the sediment sampling section (upstream), the turbidity meter, and the Parshall flume (downstream) is sufficient to avoid any interference, without permitting any increase in flow (Figure 1).

Flow rate $Q$ and turbidity were recorded every $10 \mathrm{~min}$ using a data logger with a 20-day storage capacity. The sensor windows of the turbidity probe were cleaned weekly, to limit fouling. The turbidity monitoring equipment was manufactured in Brazil (Solar Instrumentação Monitoração e Controle Ltda). The sensor (SL 2000-TS) functioned in the backscattering mode and possessed the following characteristics: (a) infrared wavelength 0.7 to $300 \mu \mathrm{m}$; (b) daylight filter; (c) 0 to $5000 \mathrm{mg}^{-1}$ concentration range.

\section{Sensor calibration}

As indicated above, there are two important aspects to consider when using turbidity meters to estimate sediment concentration (Finlayson, 1985). The first is to confirm that the equipment is stable and functioning consistently; the second is to calibrate the instrument, in order to convert the turbidity record to an estimate of in-stream SSC. For the first, the literature recommends calibration using a standardized suspension, e.g. formazin (Vanous et al., 1982). For the second, a specific calibration curve is established for the sampling site, relating SSC $\left(\mathrm{mg}^{-1}\right.$ ) to turbidity expressed in formazin turbidity units (FTU) (e.g. Wass and Leeks, 1999; Old et al., 2003; Lawler, 2005). In this study, the emphasis was on the second aspect. The first step was omitted and calibration of the turbidity sensor was conducted directly 
with suspended sediment, rather than via FTU. The manufacturer had previously undertaken tests to confirm the stability and consistency of the instrument.

To standardize units, the millivolt output obtained from the turbidity meter was converted to a value representing the percentage of the light scattered by the sample, based on the instrument's scale $(0-2500 \mathrm{mV})$. The maximum reading $(2500 \mathrm{mV})$ was deemed equivalent to $100 \%$ of light scattered. The percentage scale facilitates the physical interpretation of the process and permits comparison between data from different locations. The relationship between $\mathrm{SSC}\left(\mathrm{mg}^{-1}\right)$ and the turbidity meter reading (\%) can be expected to be non-linear. The turbidity meter was calibrated to provide values of SSC using the two different approaches. The first was undertaken in situ and involved linking the measured turbidity values to the equivalent measurements of SSC obtained for suspended sediment samples collected from the vicinity of the turbidity probe, over a range of flows. The second was undertaken in the laboratory and involved using synthetic suspensions representing a range of sediment concentrations produced using the fine fraction of soil samples collected from the catchment, to establish a relationship between SSC and turbidity.

\section{In situ calibration based on sampled events}

In the study catchment, significant SSCs occur only during events of intermediate or high magnitude. The baseflow discharge is typically $50 \mathrm{l} \mathrm{s}^{-1}$ and this is associated with SSCs of approximately $20 \mathrm{mg}^{-1}$. Thus, sediment sampling was always conducted during flood events. Suspended sediment samples were collected manually from the vicinity of the turbidity probe using a USDH 48 depth-integrating suspended sediment sampler. The sampling interval during storm events ranged between 5 and $60 \mathrm{~min}$, depending on the rate of change of discharge on the rising and falling limbs of the hydrograph.

The samples collected were transported to the Sediment Laboratory of the Institute of Hydraulic Research of the UFRGS in Porto Alegre, where the SSCs were determined by evaporation. Evaporation was used in preference to filtration, in view of problems of filter clogging associated with the relatively high SSCs in the samples and the fine nature of the sediment. When determining SSC by evaporation, an adjustment must be made to take account of the dissolved solids in the sample. Therefore, a subsample of known volume was taken from the main sample and filtered. The filtrate was then evaporated to dryness, to determine the dissolved solids concentration. The concentration of dissolved solids is then subtracted from the total concentration obtained by the evaporation method (WMO, 2003). According to our results, the dissolved solids content of the samples collected from the study catchment was typically less than $20 \mathrm{mg}^{-1}$. In addition to the SSC, the particle size distribution of the suspended sediment was determined by the pipette method (Guy, 1969), when sufficient sediment was recovered from the sample.

The values of SSC for each sample were paired with their corresponding turbidity meter readings to establish the calibration relationship by least-squares regression. The calibration period extended from July 2004 until May 2005, and included eight storm events, which covered a representative range of the annual variation in catchment condition/land use and weather conditions (Table I).

Laboratory calibration based on suspensions of known concentration produced using the fine fraction of soil samples collected from the study catchment

In this case, the sediment concentrations of the suspensions produced using the soil samples collected from the catchment were regressed against the equivalent values of turbidity associated with the laboratory measurements. The soils used to make up the standard concentrations were collected from different locations in the study catchment in order to provide a representative coverage of different sediment sources and soil types. According to Minella et al. (2004), the main sediment sources in the Arvorezinha catchment are unpaved roads $(35 \%)$ and crop fields $(65 \%)$.

The soil samples were collected from a depth of $0-10 \mathrm{~cm}$ and air dried in the shade. The fine fraction (silt and clay i.e. $<63 \mu \mathrm{m}$ ) used to produce the suspensions used as concentration standards was separated using a sieve. A known weight of this sediment was placed in a

Table I. Flood events in the Arvorezinha catchment between July 2004 and May 2005 used for turbidity meter calibration

\begin{tabular}{|c|c|c|c|c|c|}
\hline \multirow[t]{2}{*}{ Date } & \multirow[t]{2}{*}{ Vegetationcover ${ }^{\mathrm{a}}$} & \multirow[t]{2}{*}{ Peak flow $\left(1 \mathrm{~s}^{-1}\right)$} & \multirow[t]{2}{*}{ Total precipitation (mm) } & \multicolumn{2}{|c|}{$\mathrm{SSC}\left(\mathrm{mg} \mathrm{l}^{-1}\right)$} \\
\hline & & & & Average & Maximum \\
\hline 15 Jul 2004 & High & $97 \cdot 16$ & $26 \cdot 4$ & 370 & 1312 \\
\hline 20 Sep 2004 & Low (1) & 174.49 & 35 & 808 & 1445 \\
\hline 22 Sep 2004 & Low (1) & $495 \cdot 19$ & $45 \cdot 9$ & 504 & 951 \\
\hline 23 Oct 2004 & Low (1) & $153 \cdot 58$ & $32 \cdot 7$ & 616 & 1484 \\
\hline 1 Apr 2005 & Low (2) & $97 \cdot 06$ & $53 \cdot 9$ & 705 & 1300 \\
\hline 11 May 2005 & Medium & $153 \cdot 58$ & $23 \cdot 7$ & 670 & 1452 \\
\hline 18 May 2005 & Medium & 1495.88 & 62 & 442 & 1881 \\
\hline 20 May 2005 & Medium & 771.03 & 35 & 235 & 596 \\
\hline
\end{tabular}

${ }^{a}$ In the crop fields. High: the soil has a high fraction $(>80 \%)$ covered by vegetation. Low (1): a few weeks after the soil has been ploughed (crop residues cover $<10 \%$ of the soil). Low (2): after harvesting the tobacco (crop residues cover 20-30\% of the soil). Medium: an intermediate fraction of the soil surface $(50-70 \%)$ is covered by vegetation. 
beaker and mixed with 11 of river water to produce a suspension of known concentration. Using this procedure, 15 suspensions were prepared, with concentrations ranging between 25 and $2171 \mathrm{mg} \mathrm{l}^{-1}$. The individual suspensions were homogenized with an electromagnetic agitator prior to taking the turbidity readings.

\section{Determination of calibration errors}

To facilitate assessment of the errors associated with the two different calibration methods, Type $1\left(e_{1}\right)$ and Type $2\left(e_{2}\right)$ errors were distinguished. Type 1 error was associated with the use of the in situ calibration method and largely reflects the scatter in the relationship between SSC and turbidity introduced by variability in the physical properties of the sediment through time and, more particularly, by variability in the grain size composition and organic matter content of the sediment, as well as by variations in the dissolved organic matter content of the stream water.

To calculate the Type 1 error, the data for the samples from the eight rainfall events, totalling 458 samples, were used. The pairs of concentration and turbidity values were listed in increasing order, based on their concentration values, and the list was divided into two sets representing the odd and even values from the ranked list, i.e. $n$ odd $\left(\mathrm{SSC}_{\mathrm{odd}}\right.$ and $\left.\mathrm{TUR}_{\mathrm{odd}}\right)$ and $n$ even $\left(\mathrm{SSC}_{\mathrm{ev}}\right.$ and $\left.\mathrm{TUR}_{\mathrm{ev}}\right)$ values. The dataset comprising the odd values was used to derive the regression equation and the set of even values was used to determine the error associated with the calibration relationship. For the latter, the $\mathrm{TUR}_{\mathrm{ev}}$ values were substituted into the calibration equation to calculate the corresponding suspended sediment values $\left(\mathrm{SSC}_{\text {calc }}\right)$. The error was determined by comparing the $\mathrm{SSC}_{\text {calc }}$ values with the measured concentration values $\left(\mathrm{SSC}_{\text {meas }}\right)$ for the $n$ samples in the even set. The rootmean-square error was then calculated:

$$
e_{1}=\sqrt{\frac{\sum\left(\mathrm{SSC}_{\mathrm{calc}}-\mathrm{SSC}_{\text {meas }}\right)^{2}}{n-1}}
$$

Type 2 error refers to the errors introduced when calibrating the turbidity meter in the laboratory using suspensions produced using the fine fraction of soils collected in the catchment. To determine this error, the 458 pairs of samples ( $\mathrm{SSC}_{\text {meas }}$ and TUR) were again used. The turbidity values were substituted into the regression equation and a set of concentration values was obtained $\left(\mathrm{SSC}_{\text {soil }}\right)$. The average error in SSC associated with the soil method calibration was again established, using

$$
e_{2}=\sqrt{\frac{\sum\left(\mathrm{SSC}_{\text {soil }}-\mathrm{SSC}_{\text {meas }}\right)^{2}}{n-1}}
$$

where $\mathrm{SSC}_{\text {meas }}\left(\mathrm{mg}^{-1}\right)$ refers to the in situ $\mathrm{SSC}$ and $\mathrm{SSC}_{\text {soil }}$ refers to the sediment concentration estimated using the laboratory-derived calibration equation based on the synthetic sediment samples produced from the soil samples collected from the catchment.

\section{RESULTS}

\section{The variation of turbidity and suspended sediment concentration during individual rainfall events}

The variation of the turbidity signal (TUR) and the $\mathrm{SSC}_{\text {meas }}$ values during the eight events used in this study are presented in Figure 2. These plots demonstrate that the two variables are closely related. Even during the more complex events, with many individual peaks and troughs of different magnitude, the turbidity meter was sensitive to the changes in sediment concentration, as shown, for example, by the events of 15 July, 22 September and 18 May. The relationships between $\mathrm{SSC}_{\text {meas }}$ and TUR for the eight individual events shown in Figure 2 are plotted in Figure 3. These plots further confirm the existence of a close relationship between SSC and turbidity in the study catchment, although the scatter in the relationship evident in some of the plots, the existence of hysteresis in several of the plots (such as that for the event that occurred on 23 June 2004) and some differences between the precise form of the relationship for the individual events emphasizes that turbidity cannot provide a perfect surrogate for SSC.

Based on the data sets presented in Figure 3, different forms of fitted curve were tested to relate the measured sediment concentrations to the turbidity readings. Three families of equations were found to fit the data plots; namely, quadratic polynomial and power equations with three parameters, and power equations with two parameters. The best levels of fit, as measured by the correlation coefficient, were, however, obtained with the latter equations (Table II). The standard error refers to the average error per event in milligrams per litre.

As shown by the regression equations listed in Table II, the coefficients associated with the fitted curves differed between the individual events. The variability of these coefficients demonstrates the need to calibrate the turbidity meter over a range of events, in order to take account of the various factors influencing the relationship between SSC and turbidity and thus generate a calibration relationship which is generally applicable to the turbidity record obtained from a catchment.

Table II. Regression equations for relationships between SSC and TUR for individual monitored events in the Arvorezinha catchment between July 2004 and May 2005

\begin{tabular}{lccc}
\hline Date & Regression equation & $r^{2}$ & $\begin{array}{c}\text { Standard error } \\
\left(\mathrm{mg} \mathrm{l}^{-1}\right)\end{array}$ \\
\hline 15 Jul 2004 & SSC $=0.132 \times \mathrm{TUR}^{2 \cdot 204}$ & 0.960 & 76 \\
20 Sep 2004 & SSC $=0.017 \times \mathrm{TUR}^{2 \cdot 750}$ & 0.984 & 71 \\
22 Sep 2004 & SSC $=0.058 \times \mathrm{TUR}^{2 \cdot 446}$ & 0.941 & 52 \\
23 Oct 2004 & SSC $=0.668 \times \mathrm{TUR}^{1.831}$ & 0.809 & 185 \\
1 Apr 2005 & SSC $=0.451 \times \mathrm{TUR}^{1.908}$ & 0.887 & 117 \\
11 May 2005 & SSC $=0.304 \times \mathrm{TUR}^{2.010}$ & 0.927 & 129 \\
18 May 2005 & SSC $=0.308 \times \mathrm{TUR}^{2.069}$ & 0.820 & 208 \\
20 May 2005 & SSC $=0.448 \times \mathrm{TUR}^{1.885}$ & 0.931 & 33 \\
\hline
\end{tabular}



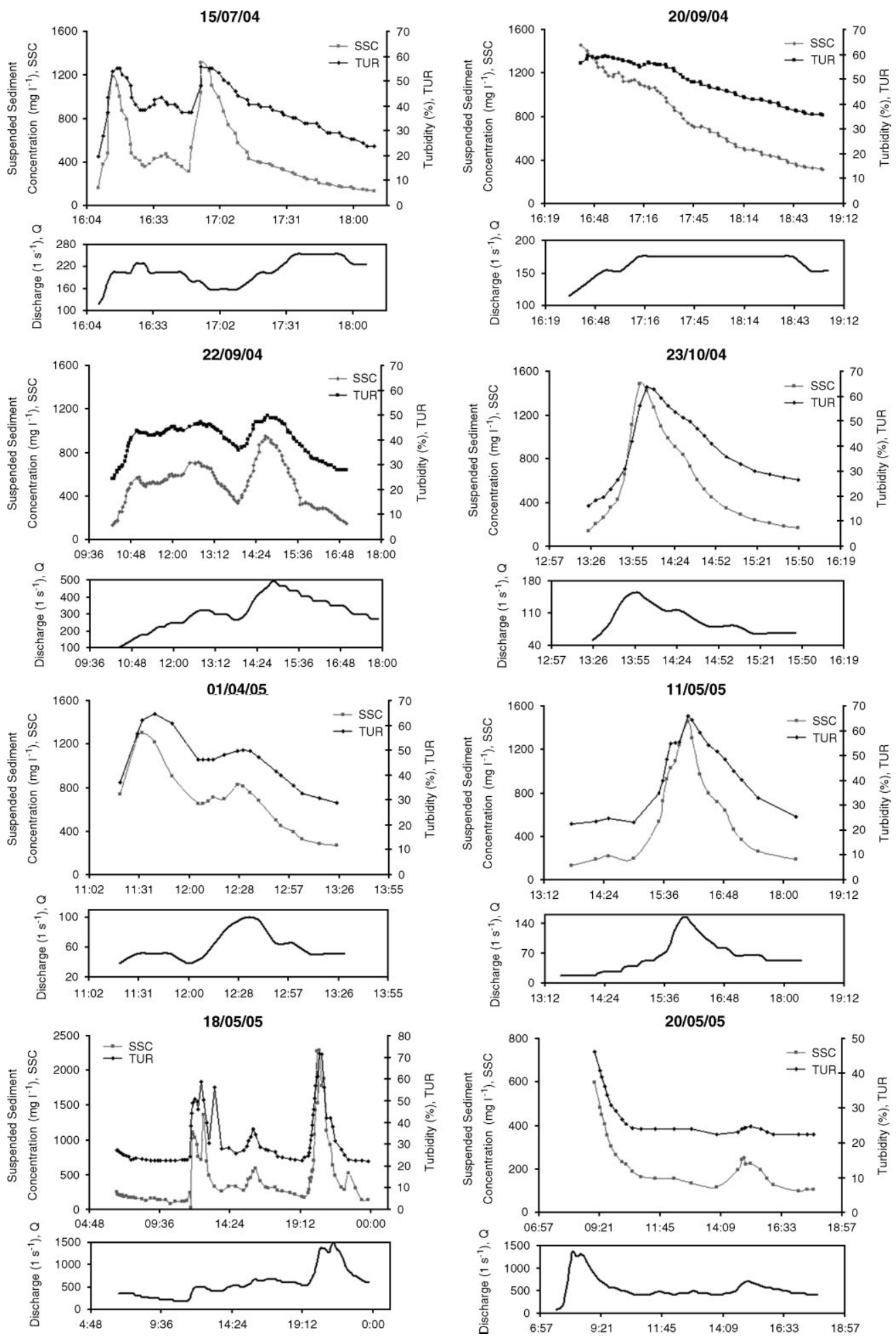

Figure 2. The variation of suspended sediment concentration ( $\mathrm{SSC}_{\text {meas }}$ ) and turbidity (TUR) during the eight monitored events

\section{A comparison of the results obtained using the two different calibration methods}

Considering first the in situ calibration, Figure 4 presents a plot of all the data pairs ( $\mathrm{SSC}_{\text {meas }}$ and TUR) assembled for the eight rainfall events. These data were used to generate a calibration relationship in order to establish the most appropriate form. Two different curve models produced a satisfactory fit: (i) a quadratic polynomial of the form $y=y_{0}+b x+a x^{2}$ with $r^{2}=0.87$ and (ii) a power equation with two parameters of the form $y=a x^{b}$ with $r^{2}=0.86$. Although the goodness of fit provided by the polynomial equation is similar to that provided by the power equation, the former is of more limited value. The quadratic polynomial function has its minimum point at $(\mathrm{TUR}=13 \cdot 71 ; \mathrm{SSC}=113.32)$ and, therefore, assumes that sediment concentrations increase when the turbidity signal falls below $13.71 \%$ and provides a minimum SSC value of $113 \mathrm{mg} \mathrm{l}^{-1}$. The power 

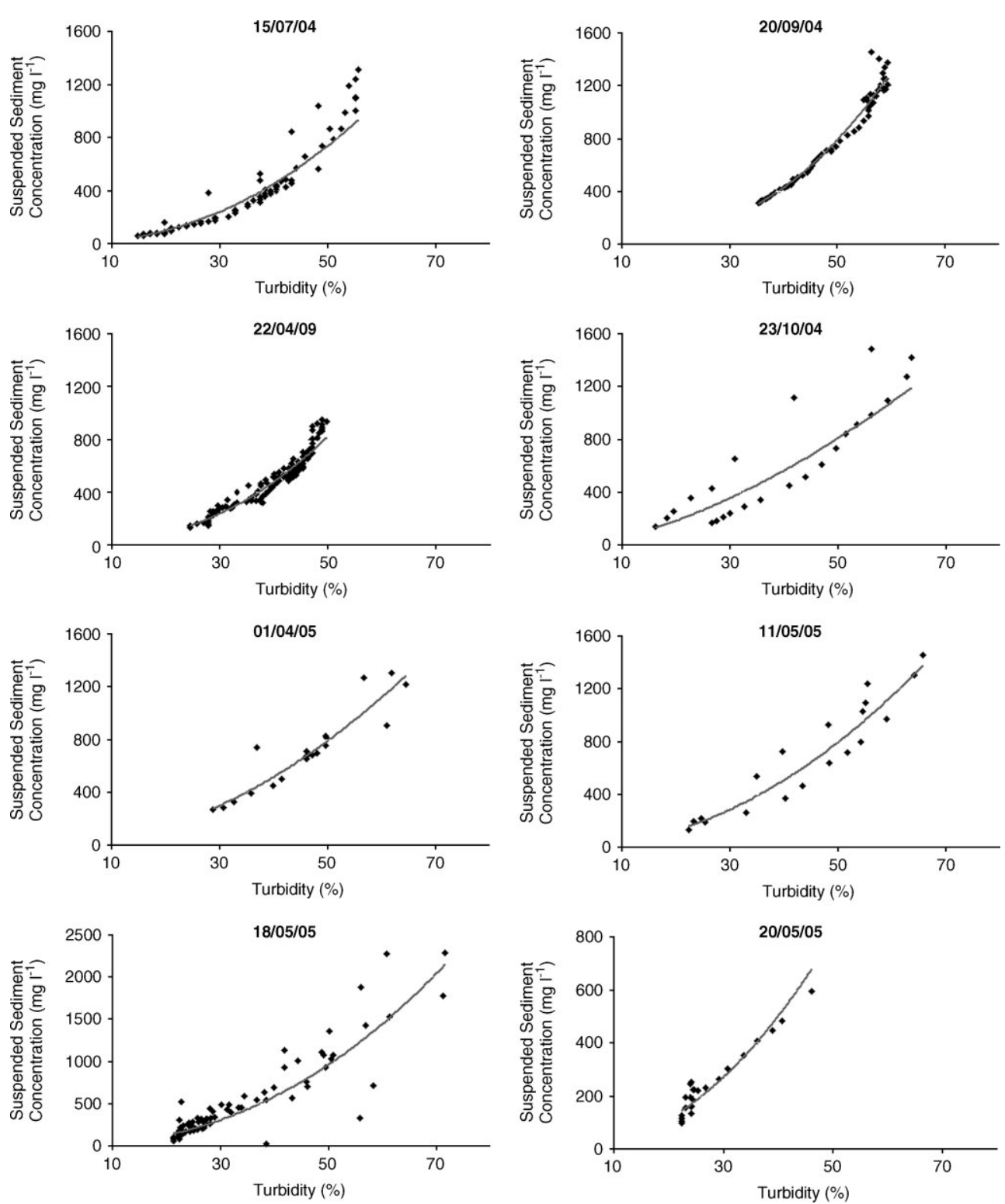

Figure 3. The relationships between the measured sediment concentrations $\left(\mathrm{SSC}_{\text {meas }}\right)$ and the turbidity signal (TUR) for the eight events monitored in the Arvorezinha catchment between July 2004 and May 2005

equation (Equation (3)) avoids these inconsistencies and was selected as providing the best representation of the calibration relationship:

$$
\mathrm{SSC}_{\text {calc }}=0.098 \times \mathrm{TUR}^{2 \cdot 313}
$$

where $\mathrm{SSC}_{\text {calc }}\left(\mathrm{mg} \mathrm{l}^{-1}\right)$ is the estimated sediment concentration and TUR (\%) is the turbidity value.

Applying the procedure for assessing the Type 1 error outlined above and using half the dataset to derive the calibration relationship and half to assess the errors associated with its application, the average error associated with the in situ calibration was estimated to be $\pm 122 \mathrm{mg}^{-1}$. This is an estimate of the average error associated with the calibration method based on event sampling, which was considered the standard methodology for this study. Figure 5 presents a plot of the predicted or $\mathrm{SSC}_{\text {calc }}$ values versus the measured values for the validation dataset. This emphasizes that the predicted values scatter around

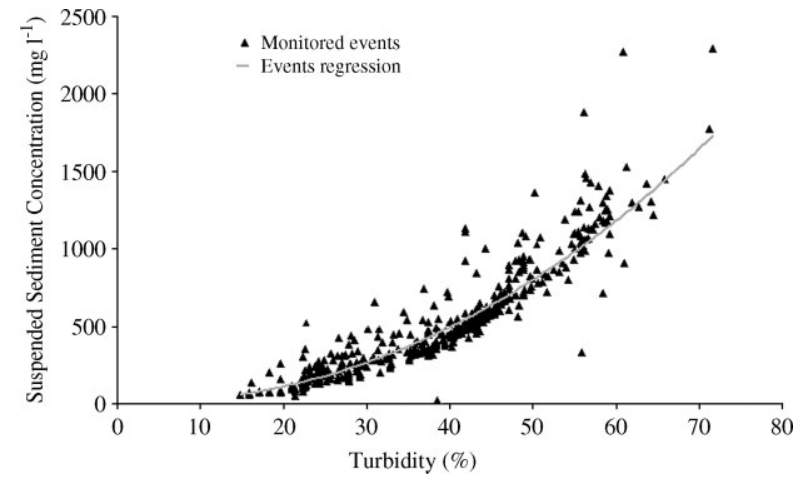

Figure 4. The dataset obtained from eight rainfall events in the Arvorezinha catchment between July 2004 and May 2005 used to assess the validity of the two calibration procedures

the 1:1 line for low and medium values of $\mathrm{SSC}_{\text {meas }}$, although there is evidence for systematic underprediction for higher values of $\mathrm{SSC}_{\text {meas }}$. Furthermore, the general 
scatter around the relationship emphasizes the sensitivity of the relationship between sediment concentration and turbidity to a range of influencing factors that vary through time.

The calibration relationship derived using the soil samples was significantly different from that based on the in situ event sampling. Figure 6 presents a plot of the relationship between sediment concentration and turbidity based on the laboratory calibration, using soil samples collected from the catchment to produce samples covering a representative range of concentrations. The power function fitted to the data plot in Figure 6, which takes the form

$$
\mathrm{SSC}_{\text {soil }}=0.569 \times \mathrm{TUR}^{2.039}
$$

provides quite a good fit to the data plot $\left(r^{2}=0 \cdot 807\right)$. The errors associated with using Equation (4) to convert the turbidity record obtained for the stream to a record of SSC were assessed using the set of 458 samples collected from the study catchment and comparing the measured values of sediment concentration obtained for these samples with the values estimated from the

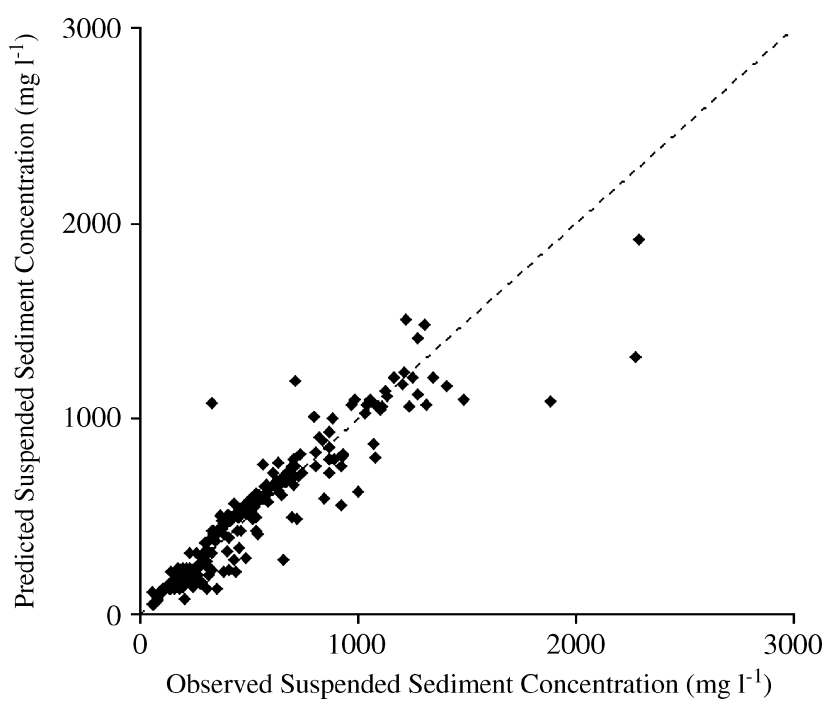

Figure 5. The relationship between predicted and observed values of SSC obtained for the in situ calibration procedure using the split dataset

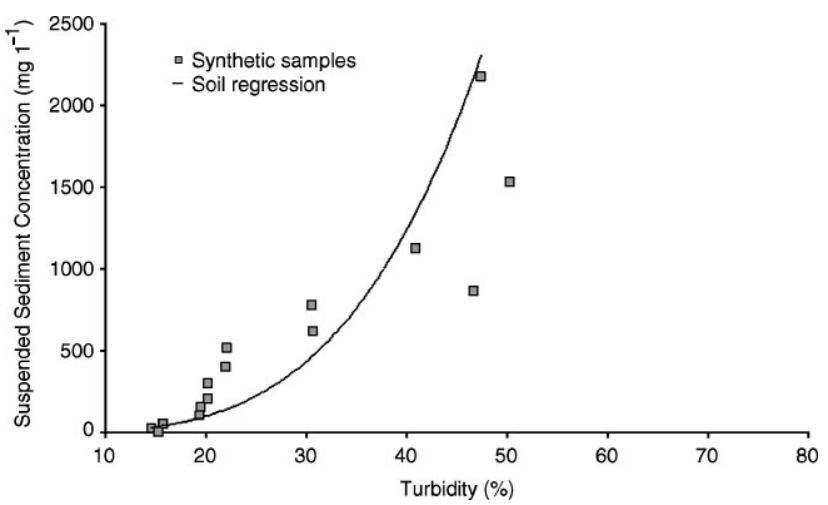

Figure 6. A plot of the data obtained from the laboratory-based calibration procedure. This was based on 15 samples covering a range of different concentrations prepared using the $<63 \mu \mathrm{m}$ fraction of representative soil samples collected from the Arvorezinha catchment turbidity value recorded at the time the sample was collected. The root-mean-square error associated with using Equation (4) to estimate the SSC from the turbidity recorded in the stream was calculated using Equation (2). The error based on the 458 samples was $+601 \mathrm{mg}^{-1}$. This value is about five times greater than the value obtained for the calibration relationship based on in situ calibration using samples collected during storm events. The positive value indicates that the estimates of SSC obtained using Equation (4) consistently overestimate the measured sediment concentrations. The magnitude and nature of the errors associated with using the laboratory calibration procedure, based on soil samples, is explored further in Figure 7, which presents a plot of the sediment concentrations predicted using the calibration relationship ( $\left.\mathrm{SSC}_{\text {soil }}\right)$ versus the measured sediment concentrations $\left(\mathrm{SSC}_{\text {meas }}\right)$. This plot emphasizes the general overestimation associated with this calibration procedure and the tendency for the degree of overestimation to increase for higher concentration values. For concentration values in the range 100 to $1800 \mathrm{mg} \mathrm{l}^{-1}$, the error or overestimation is typically $\sim 80 \%$, which must be seen as high.

Figure 8 further assesses the accuracy of the estimates of SSC obtained from the recorded turbidity values using the in situ or field calibration (Equation (3)) and the laboratory calibration based on the soil samples (Equation (4)), by comparing both values. The difference between the estimates of SSC provided by the two calibration relationships can be seen to vary according to the magnitude of the turbidity value. For turbidity values $<35 \%$, the values of SSC estimated using the laboratory calibration (Equation (4)) are more than $100 \%$ greater than those estimated using the field-based calibration (Equation (3)). For turbidity values $>35 \%$, the estimates of SSC provided by Equation (4) are $80-100 \%$ greater

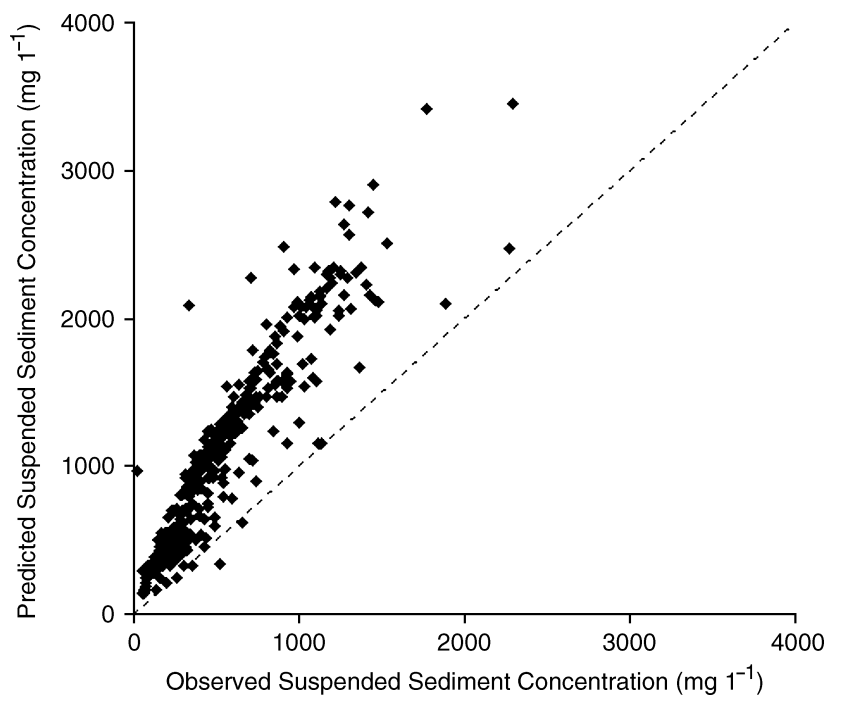

Figure 7. The relationship between predicted and observed values of SSC obtained using the laboratory-derived calibration relationship applied to the full set of turbidity and sediment concentration measurements 
than those provided by Equation (3) are. The overestimation associated with Equation (4) and the laboratorybased calibration reflects contrasts in grain size composition between the fine soil fractions used for the laboratory calibration and the suspended sediment transported by the stream. The nature of this contrast is shown in Table III, which compares average values of percentage silt and percentage clay for the suspended sediment used for the in situ calibration with those for the fine fraction of the soil used for the laboratory calibration. Table III indicates that the proportion of clay-sized particles is significantly higher in the river sediment. Since turbidity values are highly sensitive to the grain size composition of the sediment, with finer sediment generating a much higher turbidity for a given concentration (e.g. Lawler, 2005), a given concentration of suspended sediment will be associated with a much higher turbidity than the same concentration of soil.

\section{DISCUSSION}

\section{The calibration methods compared}

The results presented above demonstrate that, in the study catchment, turbidity provides an effective surrogate for SSC, since the two variables show similar trends during storm runoff events (Figure 2) and Figure 3 demonstrates a clear positive relationship between the measured sediment concentrations and the equivalent turbidity values. However, the data used in the in situ field calibration were clearly far more representative of suspended sediment transport in the study catchment and, thus, provided a more meaningful and reliable calibration relationship

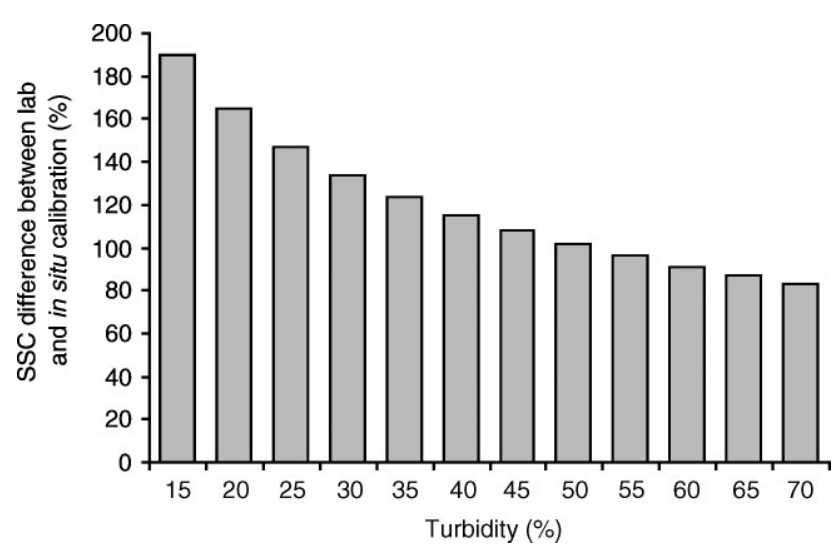

Figure 8. Differences between the SSC estimates obtained for the same turbidity value, using the two calibration procedures (Equations (3) and (4)), for a range of turbidity levels

Table III. The grain size composition of the sediment used for calibration

\begin{tabular}{lcc}
\hline Sediment type & Silt (\%) & Clay (\%) \\
\hline Fluvial sediment & $55 \cdot 3^{\mathrm{a}}$ & $44 \cdot 7^{\mathrm{a}}$ \\
Soil fine fraction & $73 \cdot 3$ & $22 \cdot 7$ \\
\hline
\end{tabular}

${ }^{a}$ Mean values for calibration samples. than the laboratory calibration based on soil samples. The magnitude of the errors associated with use of the laboratory calibration is such as to make the resulting concentration record unrepresentative of the true record and, thus, of limited value. Three key features of the field calibration procedure served to optimize the resulting calibration relationship. The first was the inclusion of measurements spanning a wide range of concentration values (i.e. $20-2400 \mathrm{mg} \mathrm{l}^{-1}$ ). This avoided the need to extrapolate the fitted calibration relationship, since this range includes almost all the concentrations sampled since monitoring began in 2002. The second is that, for six of the eight events that were sampled, the sampling spanned the full duration of the event and, therefore, the data used to establish the calibration relationship included information relating to both rising and falling limb conditions. It is well known that the sediment dynamics of a catchment may exhibit significant contrasts between the rising and falling limbs of a storm hydrograph. The third was the substantial number of samples used to establish the calibration relationship, since this ensured that the regression relationship provided a meaningful representation of the average conditions in the catchment.

The laboratory calibration method, which uses soil samples collected from the catchment, potentially offers several important advantages over the in situ calibration procedure, including speed, ease of application, the possibility of generating as many concentrations as desired (thus avoiding dependence on natural events to cover the range of concentration required) and, finally, avoiding delays in obtaining sufficient data to establish the calibration relationship and, therefore, processing the turbidity record. However, the results presented above clearly demonstrate that the laboratory-based calibration procedure has major limitations that can give rise to significant errors in the concentration values derived from the turbidity record. These limitations reflect, first, the fact that the physical and geochemical characteristics of the fine fraction of the soil samples collected from the catchment may not be representative of those of the suspended sediment transported by the river. Contrasts between the two may reflect the failure of the soil samples to include the full range of sediment source materials within the catchment and to take account of the relative importance of those sources. Equally, differences in grain size composition and organic matter content between the soil and suspended sediment samples will be reflected by different concentration-turbidity relationships. As indicated previously, the size and shape of the particles affects the refraction angle of the light rays and, thus, the turbidity reading. Similarly, the amount of particulate and soluble organic matter in the soil samples may not be the same as that associated with suspended sediment collected during storm events. Second, the samples of varying sediment concentration made up in the laboratory cannot reflect the considerable temporal variability in the properties of the suspended sediment transported by the stream, or the 
variability in the geochemistry of the stream water carrying the suspended sediment. Both will influence the concentration-turbidity relationship.

Although it is clear that the field-based in situ calibration procedure provides more accurate and reliable estimates of SSC than the laboratory-based procedure using soil samples and that the laboratory-based procedure cannot be seen as a viable alternative to in situ field calibration, it must be recognized that the former approach necessarily involves several limitations, as indicated above. More particularly, it may be difficult to visit a remote site during infrequent storm events, in order to undertake the calibration measurements and to cover a representative range of concentration values. Furthermore, there may be a significant delay between the installation of turbidity monitoring equipment and the establishment of a reliable calibration relationship that can be used to convert the turbidity record to a reliable record of SSC.

\section{Using turbidity measurements in sediment monitoring programmes in Brazil}

One of the main problems facing fluvial sediment monitoring programmes in Brazil has been the lack of reliable methods for obtaining a detailed time series of SSC to combine with the continuous discharge record. In Brazil, estimates of sediment flux in the major rivers have commonly been obtained by using sediment rating curves, which provide a general relationship between SSC and water discharge, and which can in turn be used to estimate values of sediment concentration from the discharge record for use in estimating the suspended sediment load. However, it is increasingly recognized that such rating curves are unlikely to provide reliable estimates of the annual sediment load of a river (e.g. Walling and Webb, 1988), and the errors associated with estimates of shorter-term loads may be even greater. The lack of synchronization between the hydrograph and the sediment graph and the progressive exhaustion of the sediment supply that frequently occurs during a sequence of events represent important constraints when attempting to use a sediment rating curve to estimate the sediment concentration from the discharge record. Furthermore, in Brazil, sediment rating curves are often based on as few as four random samples per year and these samples may not coincide with flood events. Equally, use of samples collected over an extended period may introduce problems where the sediment response of a river cannot be assumed to be stationary, because of land-use change or reservoir construction. Recent work reported by Merten et al. (2006) suggests that the estimates of sediment flux obtained for the major rivers of Brazil using the rating curve approach may underestimate the loads by as much as $60 \%$.

Against this background, the possibility of using automated technologies for continuously recording SSC potentially represents an important advance towards the goal of obtaining accurate sediment data in Brazil. Turbidity meters, in particular, would appear to have a promising future in Brazil, especially since they are already being produced domestically. However, these instruments are still not widely used in Brazil. There are few studies that have compared turbidity data with information obtained using traditional sampling methods, and there are currently no accepted protocols to guide the installation and calibration of turbidity recording equipment. To date, this information has been provided primarily by the manufacturers, with little consideration of the possible problems involved. For this reason, laboratory calibration using soils has been used in some cases in Brazil due to the ease of use and low cost. Nonetheless, the uncertainties involved in this calibration method may result in SSC data that have little in common with the actual values, thus eliminating the advantages potentially offered by continuous SSC measurement.

\section{CONCLUSIONS}

Evaluation of two methods for generating a calibration relationship relating SSC and turbidity showed that calibration using traditional field sampling during a sequence of flood events was much more effective than calibration in the laboratory using the fine $(<63 \mu \mathrm{m})$ fraction of soil samples collected from the catchment area upstream of a measuring site. The calibration method using field data gave a mean error of $\pm 122 \mathrm{mg} \mathrm{l}^{-1}$, whereas the laboratory calibration procedure resulted in a mean error of $+601 \mathrm{mg}^{-1}$. Estimates of SSC based on equations obtained using the laboratory calibration method consistently overestimated the values based on traditional sampling techniques. This overestimation can be attributed to the coarser size distribution of the soil material used for the laboratory calibration method, relative to suspended sediment.

The results obtained from this study emphasize that the laboratory calibration method generates inferior and unreliable results, when compared with those provided by field-based calibration. Considering the complex nature of the relationship between SSC and turbidity, reflecting the influence of factors such as particle size and shape and water colour, it is important that the calibration method should adequately represent these naturally occurring variations, which are difficult to replicate in a laboratory setting.

\section{ACKNOWLEDGEMENTS}

The help provided by EMBRAPA CNPT, especially Dr Eloir Denardin, in loaning monitoring equipment, by field technicians Ademir and Adair Giongo through their careful sampling, and by Elena Metcalf in translating the manuscript, is gratefully acknowledged. We would particularly like to thank Professor Des Walling (University of Exeter) for very important discussions of the work. The study received financial support from the Brazilian National Research Council-CNPq, FAPERGS and SINDIFUMO. 


\section{REFERENCES}

Bordas MP, Semmelmann FR. 1997. Elementos de engenharia de sedimentos. In Hidrologia: Ciência e Aplicação, 2, Tucci CE (org.). ABRH, Editora da Universidade: Porto Alegre; 915-939.

Carvalho NO. 1994. Hidrossedimentologia Prática. CPRM: Rio de Janeiro.

Davies-Colley RJ, Smith DG. 2001. Turbidity, suspended sediment, and water clarity: a review. Journal of American Water Resources Association 37: 1085-1101.

Droppo IG, Nackaerts K, Walling DE, Williams N. 2005. Can flocs and water stable soil aggregates be differentiated within fluvial systems? Catena 60: 1-18.

Dunne T. 1979. Sediment yield and land use in tropical catchments. Journal of Hydrology 42: 281-300.

Finlayson BL. 1985. Field calibration of a recording turbidity meter. Catena 12: $141-147$.

Foster IDL, Millington R, Grew RG. 1992. The impact of particle size controls on stream turbidity measurement; some implications for suspend sediment yield estimation. In Erosion and Sediment Transport Monitoring Programmes in River Basins, Bogen J, Walling DE, Day TJ (eds). IAHS Publication No. 210. IAHS Press: Wallingford; $51-62$.

Gippel CJ. 1995. Potential of turbidity monitoring for measuring the transport of suspend solids in streams. Hydrological Processes 9: 83-97.

Glysson GD, Gray Jr. 2002. Total suspended solids data for use in sediment studies. In Proceedings of the Federal Interagency Workshop on Turbidity and Other Sediment Surrogates, Reno, NV; Appendix 2.

Guy HP. 1969. Laboratory theory and methods for sediment analysis. In Laboratory Analysis, Section C: Sediment Analysis. US Geological Survey Techniques of Water Resources Investigations, Book 5. United States Geological Survey.

Horowitz AJ, Elrick KA. 1987. The relation of stream sediment surface area, grain size and composition to trace element chemistry. Applied Geochemistry 2: 437-451.

Kasai M, Brierley GJ, Page MJ, Marutami T, Trustrum NA. 2005. Impacts of land use change on patterns of sediment flux in Weraamaia catchment, New Zealand. Catena 64: 27-60.

Kimoto A, Uschida T, Mizuyama T, Changhua L. 2002. Influences of human activities on sediment discharge from devastated weathered granite hills of southern China: effects of 4-year elimination of human activities. Catena 48: 217-233.

Landers MN. 2002. Summary of blind sediment reference sample measurement session. In Proceedings of the Federal Interagency Workshop on Turbidity and Other Sediment Surrogates, Reno, NV; 29-30.

Lane LJ, Hernandez M, Nichols M. 1997. Processes controlling sediment yield from watersheds as functions of spatial scale. Environmental Modelling and Software 12: 355-369.

Lawler DM. 2005. Turbidity and nephelometry. In Encyclopedia of Analytical Science, 2nd edn, Worsfold PJ, Townshend A, Poole CF (eds). Elselvier: 343-351.

Lawler DM, Brown RM. 1992. A simple and inexpensive turbidity meter for estimation of suspend sediment concentration. Hydrological Processes 6: 159-168.

Lawler DM, Petts GE, Foster IDL, Harper S. 2006. Turbidity dynamics during spring storm events in an urban headwater river system: the Upper Tame, West Midlands, UK. Science of the Total Environmental 360: $109-126$.

Lewis J. 2002. Estimation of suspended sediment flux in streams using continuous turbidity and flow data coupled with laboratory concentrations. In Proceedings of the Federal Interagency Workshop on Turbidity and Other Sediment Surrogates, Reno, NV; Appendix 2.

Martin CE, McCulloch MT. 1999. Nd-Sr isotopic and trace element geochemistry of river sediments and soils in a fertilized catchment, New South Wales, Australia. Geochimica et Cosmochimica Acta 63 : 287-305.

Minella JPG. 2003. Identificação de fontes de produção de sedimentos em uma pequena bacia rural. Dissertação de Mestrado, Programa de
Pós-Graduação em Recursos Hídricos e Saneamento Ambiental, Instituto de Pesquisas Hidráulicas, Universidade Federal do Rio Grande do Sul.

Minella JPG, Merten GH, Clarke RT. 2004. Identification of sediment sources in a small rural watershed. In Sediment Transfer Through the Fluvial System, Gosolov V, Belyaev V, Walling DE (eds). IAHS Publication No. 288. IAHS Press: Wallingford; 44-51.

Merten GH, Minella JPG. 2005. Impact on sediment yield due to intensification of tobacco production in a catchment in southern Brazil. In Sediment Budgets, Horowitz AJ, Walling DE (eds). IAHS Publication No. 292. IAHS Press: Wallingford; 119-126.

Merten GH, Horowitz AJ, Clarke RT, Minella JPG, Pickbrenner K, Pinto MCF. 2006. Considerações sobre a utilização da curva-chave para determinação de fluxo de sedimentos. In Anais do 7. Encontro Nacional de Engenharia de Sedimentos, Associação Brasileira de Recursos Hídricos: Porto Alegre, RS, Brazil.

Morgan RPC. 1995. Soil Erosion and Conservation, 2nd edn. Longman Science and Technical/Wiley: Harlow/New York.

Old GH, Leeks GJL, Packman JC, Smith BPG, Lewis S, Hewitt EJ, Holmes M, Young A. 2003. The impact of a convectional summer rainfall event on river flow and fine sediment transport in a highly urbanised catchment Bradford, West Yorkshire. The Science of the Total Environmental 314: 495-512.

Owens PN, Walling DE. 2002. The phosphorous content of fluvial sediment in rural and industrialized river basins. Water Research 36: 685-701.

Peart MR, Walling DE. 1982. Particle size characteristics of fluvial suspend sediment. In Recent Developments in the Explanation and Prediction of Erosion and Sediment Yields, Walling DE (ed.). IAHS Publication No. 137. IAHS Press: Wallingford; 397-407.

Schoellhamer DH. 2002. Use of optical properties to monitor turbidity and suspended-sediment concentration. In Proceedings of the Federal Interagency Workshop on Turbidity and other sediment surrogates, Reno, NV; 15-16.

Souza PK. 2005. Instrumentos de Medida e Sistemas de Instrumentação. Instituto de Pesquisas Hidráulicas, Universidade Federal do Rio Grande do Sul: Porto Alegre, RS.

Teixeira EC, Caliari PC. 2005. Estimation of the concentration of suspended solids in rivers from turbidity measurement: error assessment. In Sediment Budgets 1, Walling DE, Horowitz AJ (eds). IAHS Publication No. 291. IAHS Press: Wallingford; 151-160.

USDA. 1975. Soil Taxonomy: A Basic System of Soil Classification for Making and Interpreting Soil Surveys. US Department of Agriculture Handbook 436. US Government Printing Office: Washington, DC.

Vanous RD, Larson PE, Hach CC. 1982. The theory and measurement of turbidity and residue. In Water Analysis, vol. 1, Minear RA, Keith LH (eds). Academic Press: New York.

Walling DE. 2006. Human impact on land-ocean sediment transfer by the world's rivers. Geomorphology 79: 192-216.

Walling DE, Collins AL. 2000. Integrated Assessment of Catchment Sediment Budgets: A Technical Manual. Department for International Development: Exeter.

Walling DE, Webb BW. 1981. The reliability of suspend sediment load data. In Erosion and Sediment Transport Measurement. IAHS Publication No. 133. IAHS Press: Wallingford; 177-194.

Walling DE, Webb BW. 1988. The reliability of rating curve estimates. In Sediment Budgets, Bordas MP, Walling DE (eds). IAHS Publication No. 174. IAHS Press: Wallingford; 337-350.

Walling DE, Owens PN, Carter J, Leeks GJL, Lewis S, Meharg AA, Wright J. 2003. Storage of sediment-associated nutrients and contaminants in river channel and floodplain systems. Applied Geochemistry 18: 195-220.

Wass PD, Leeks GJL. 1999. Suspended sediment fluxes in the Humber catchment, UK. Hydrological Processes 13: 935-953.

Williams GP. 1989. Sediment concentration versus water discharge during single hydrologic events. Journal of Hydrology 111: 89-106.

WMO. 2003. Manual on Sediment Management and Measurement. World Meteorological Organization: Geneva. 